Violetta KraWCZYK-WASILEWSKA

Uniwersytet Łódzki

Wydział Filozoficzno-Historyczny

Instytut Etnologii i Antropologii Kulturowej

\title{
OD LOKALNYCH ŚWIATÓW DO GLOBALNEJ WIOSKI. ProblematyKa EUROPEJSKIEgO DZIEDZICTWA KULTUROWEGO JAKO ELEMENT POLITYKI UNIJNEJ
}

Problematyka konotacji definicyjnych pojęcia tożsamość (wprowadzonego do nauk społecznych w latach pięćdziesiątych XX w. ${ }^{1}$ ) wciąż stanowi przedmiot ożywionej dyskusji naukowej². Dyskusja ta dotyczy zarówno problematyki autoidentyfikacji jednostki, jak również rodzajów tożsamości wynikających z relacji między indywidualnym przeżywaniem własnej egzystencji a formami interakcjonizmu określonej społeczności, a więc nie tylko stosunku do siebie samego i innych ludzi, ale też do grup, wspólnot i narodów, a zatem do kultury i tradycji ${ }^{3}$.Współcześnie bowiem zagadnienie tożsamości etniczno-kulturowej nabiera nowego wymiaru już nie tylko jako element dyskursu o prawach człowieka, akceptacji i tolerancji jego kultury, ale też jako ważki czynnik polityczny związany z postępującą globalizacją i procesem integracji narodów Europy ${ }^{4}$.

${ }^{1}$ E. H. Erikson, The Problem of Ego Identity, ,Journal of American Psychoalalytical Association" 1956, nr 4, s. 56-121; tenże, Identity and Life Cycle. Selected Papers, Intl. Univ. Press, New York 1959. Por. przekład Dopełniony cykl życia, Rebis, Poznań 2002.

2 A. Cohen, Self Consciousness: An Alternative Anthropology of Identity, Routledge, London 1994; The Politics of Multiculturalism in the New Europe: Racism, Identity and Community, pod red. T. Modooda i P. Werbnera, Zed Books, London 1997; K. Woodward, Questioning Identity: Gender, Class, Ethnicity, Routledge, London 2004.

${ }^{3}$ V. Krawczyk-Wasilewska, Tożsamość podmiotu zbiorowego $w$ dobie globalizacji. Wybrane zagadnienia, [w:] Zagrożenie tożsamości? Problematyka globalizacji w zainteresowaniach polskiej antropologii, pod red. A. Nadolskiej-Styczyńskiej,seria wyd. „Archiwum Etnograficzne”, t. 43, PTL, Wrocław-Łódź 2005, s. 45-48.

${ }^{4}$ Por. Globalizacja i integracja europejska, pod red. B. Jóźwika, Wydawnictwo KUL, Lublin 2007. 
Nie bez znaczenia będzie tu zwrócenie uwagi na fakt powolnego odchodzenia od modelu monolitycznego państwa narodowego na rzecz tworzenia struktur federacyjnych, składających się z mniejszych, a nawet małych, lecz silnych gospodarczo i kulturowo regionów demokratycznie współpracujących ze sobą. Skłonności tej towarzyszy tworzenie struktur ponadpaństwowych (Unia Europejska) oraz globalnych współzależności międzypaństwowych w ramach systemowych układów politycznych, gospodarczych, militarnych i kulturalnych (np. ONZ, NATO, UNESCO). Z kolei rozwojowi struktur transnarodowych towarzyszy proces globalizacyjny ${ }^{5}$, obejmujący różnorakie relacje, od gospodarczych (zwłaszcza handlowych i bankowych) poprzez polityczne (np. antyterroryzm), aż po kulturę masową i obyczajową. Intensywność tych relacji wzmógł rewolucyjny postęp technologiczny w sferze informacji i komunikacji, a zwłaszcza upowszechnienie (od 1990 r.) globalnego systemu informatycznego zwanego Internetem.

Wobec narastających procesów globalizacyjnych współczesnego świata, znaczonych drogą współzależności ekonomicznych, wymiany idei i informacji oraz mobilnością ludzi, poszukiwanie korzeni i odniesień kulturowych człowieka odzwierciedla naturalną potrzebę jednostki, jaką jest poczucie przynależności etniczno-kulturowej i wiedzy o własnym pochodzeniu oraz swojej małej ojczyźnie ${ }^{6}$. Przypomnieć tu też należy, iż organizacją każdego życia społecznego kierują dwie podstawowe zasady, jako to: wspólnotowa (związana z pokrewieństwem, sąsiedztwem, przyjaźnią i naturalnością stosunków międzyludzkich) i zrzeszeniowa (związana z przestrzeganiem

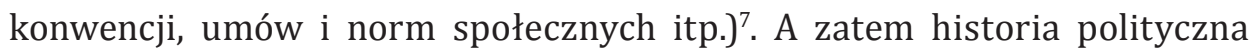
i kulturowa danego państwa i narodu nieodłącznie wiąże się z pojęciem

${ }^{5}$ Pojęciem globalizacji określa się proces internacjonalizacji o zasięgu światowym, w którym narastają wzajemne powiązania państw i społeczeństw położonych od siebie w znacznej odległości geograficznej. Por:: The Globalization of World Politics: An Introduction to International Relations, pod red. J. Baylisa i S. Smitha, Oxford Univ. Press, Oxford 1997; R. Robertson, Globalization: Social Theory and Global Culture, Sage, London 1992; Z. Bauman, Globalizacja i co z tego dla ludzi wynika, PIW, Warszawa 2007.

${ }^{6}$ M. Wieruszewska, Tożsamość kulturowa jako wartość i czynnik konstruktywny społeczności lokalnej, Wydawnictwo Uniwersytetu Warszawskiego, Warszawa 1989; S. Bednarek, W kręgu małych ojczyzn. Szkice regionalistyczne, KODRTK, Wrocław-Ciechanów 1996; Ja - regionalista. Refleksje, stanowiska, komentarze, pod red. D. Kasprzyka, Interdyscyplinarny Zespół Badania Wsi UŁ, Łódź 2010.

${ }^{7} \mathrm{Na}$ zasady te zwracało uwagę wielu uznanych badaczy społecznych (F. Znaniecki, M. Mead, S. Ossowski, B. Anderson, M. Weber, F. Tönnies i inni). 
tożsamości i dziedzictwa, ponieważ mają one znaczenie $\mathrm{w}$ budowaniu procesu identyfikacji ludzi i etnosów.

Zanim przejdziemy do idei wspólnoty kulturowej Europy, podkreślić musimy, iż koncepcja wspólnego, europejskiego dziedzictwa kulturowego już po II wojnie światowej funkcjonowała jako element współpracy pokojowej, torujący bardzo powoli drogę pojęciu tożsamości europejskiej jako istotnemu warunkowi późniejszej integracji politycznej i ekonomicznej. Nie bez znaczenia był też fakt, iż do strat wojennych po II wojnie światowej zalicza się również grabież dziedzictwa kultury ${ }^{8}$, dokonaną zarówno przez Trzecią Rzeszę, jak i aliantów. Świadczyło to, że prawodawstwo międzynarodowe z końca XIX i I poł. XX stulecia (zwłaszcza tzw. konwencje haskie i zalecenia Ligi Narodów) okazały się daleko niewystarczające.

Jednakowoż w wielu państwach europejskich zarówno deficyt demokracji, jak również brak poparcia dla idei integracyjnej nie pomagał, mimo proklamowania w 1973 r. Deklaracji tzw. kopenhaskiej, dotyczącej tożsamości europejskiej [Declaration on European Identity]. Deklaracja ta była pierwszą próbą definicji tożsamości europejskiej w oparciu o wspólne wartości, takie jak: prawa człowieka, demokracja i państwo prawa. Dopiero rok 1983 przyniósł Uroczystą Deklarację w Sprawie Unii Europejskiej (tzw. stuttgarcką), w której postanowiono budować poczucie wspólnoty europejskiej przez odwołanie się do dziedzictwa kulturowego. Tamże zapisano, iż działalność Rady Europy ma obejmować współpracę kulturalną „w celu potwierdzenia świadomości wspólnego dziedzictwa kulturowego jako elementu tożsamości europejskiej"9.

Współcześni mieszkańcy Europy, zarówno zachodniej, jak i wschodniej oraz centralnej mogą się różnić poglądami na temat ich własnej tożsamości, przynależności politycznej i obywatelskości, ale jako Europejczycy muszą stawić czoła ważnym kwestiom, wiążącym się z problematyką ochrony i obrony dziedzictwa kulturowego, wyrażającego się zarówno w sferze materialnej, jak i niematerialnej.

Pierwsza kwestia dotyczy odpowiedzi na pytanie: czy narodowe bezpieczeństwo kulturowe ma być rozumiane jako instytucjonalne tworzenie

${ }^{8}$ Por. J. Pruszyński, Dziedzictwo kultury Polski. Jego straty i ochrona prawna, t. 1-2, Wydawnictwo Zakamycze, Kraków 2001.

${ }^{9}$ Cytat powyższy i dalsze cytaty pochodzą z dokumentów prawnych ogłoszonych na stronie internetowej www.Europa.eu/en-law/treaties/index_pl (dostęp: 31.05.2013). 
warunków do utrwalania i pielęgnowania wartości decydujących o tożsamości danego społeczeństwa przy jednoczesnym czerpaniu z doświadczeń innych narodów europejskich? Drugim zagadnieniem wymagającym zastanowienia się jest pytanie o sposób w jakim zróżnicowane kulturowo tożsamości mogą koegzystować na płaszczyźnie wzajemnego poszanowania w ramach jednej i zarazem wielonarodowej wspólnoty, zamieszkującej kontynent europejski. Trzecim wreszcie problemem może być pytanie o to, czy możliwa jest satysfakcjonująca realizacja kulturowych wartości wspólnotowych jako ideału pokoju i bezpieczeństwa, nad którymi formalną pieczę sprawuje Rada Europy [Council of Europe]?

Nadmienić tu należy, że choć Rada Europy od początku swego istnienia, tj. od 1949 r. wykazywała zainteresowanie zagadnieniami kultury, to europejska problematyka kulturowa pojawiła się znacznie później, bo w 1992 r., kiedy to powstał słynny Traktat o Unii Europejskiej, zwany popularnie Traktatem z Maastricht, w którym wskazano na bogactwo i różnorodność kultury europejskiej, wymagającej ochrony i rozwoju. W następnym Traktacie o Unii (tzw. amsterdamskim) z roku 1997 zapisano co następuje: „Wspólnota przyczynia się do rozkwitu Państw Członkowskich, respektując ich narodową i regionalną różnorodność, jednocześnie uwypuklając wspólne dziedzictwo kulturowe" [art. 128]. Od tego czasu realizowane są liczne inicjatywy i programy kulturalne (między innymi „KULTURA 2000” czy „Kultura 2007-2013”), w świetle których kultura traktowana jest jako cel sprzyjający integracji, a nie środek do osiągania innych celów, ponieważ w polityce unijnej pojęcie kultury ma wymiar trójaspektowy, a mianowicie:

- jako kulturowa różnorodność i dialog międzykulturowy;

- jako twórczość;

- jako element europejskiej polityki zagranicznej.

W kampanii z lat 1999-2000, przebiegającej pod hasłem „Europa: Wspólne Dziedzictwo" powiązano problematykę dziedzictwa kulturowego z wartościami demokratycznymi i pojęciem tożsamości wspólnotowej. Kampania ta obejmowała cały kompleks projektów, których celem było podnoszenie świadomości społecznej wśród narodów całej Europy. Odtąd też są wspierane projekty współpracy pomiędzy podmiotami kulturalnymi z różnych krajów członkowskich i pozaunijnych, biorących udział w danym projekcie. Celem jest akcentowanie różnorodności kulturowej i dialogu, 
ochrona dóbr kultury i promocja twórczości oraz mobilności twórców (przy wykorzystaniu nowych technologii społeczeństwa informacyjnego) oraz uznanie kultury jako czynnika ekonomicznego i czynnika integracji społecznej oraz obywatelskiej.

Ochrona bowiem i rozwój kultury każdego narodu europejskiego powinny podlegać trosce instytucji poszczególnych państw członkowskich, ale też i samych społeczeństw. Sprzyja temu idea rozwoju demokratycznego i odpowiedzialnego społeczeństwa obywatelskiego, które - dzięki aktywnym członkom - negocjuje, spiera się, walczy lub zgadza z decyzyjnymi centrami politycznymi i ekonomicznymi. W rozwiniętym społeczeństwie partycypacyjnym jednostka ma możliwość aktywnego działania poprzez wolontariaty, stowarzyszenia, fundacje, związki, ruchy, partie i tym podobne obywatelskie organizacje społeczne.

Świadectwem takiego właśnie, obywatelskiego podejścia do problematyki dziedzictwa kulturowego była I Europejska Konferencja Organizacji Ochotniczych Na Polu Dziedzictwa Kulturowego, która odbyła się w Norwegii w 2000 r., mimo iż państwo to nie jest członkiem Unii Europejskiej. Nieprzypadkowo też gospodarzem tego spotkania było Oslo, ponieważ już w 1844 r. uformowało się tam Towarzystwo do Ochrony Starożytności Norweskich. Natomiast w 2001 r. Rada Europy dokonała wielkiej promocji idei ochrony kultury poprzez aktywizację obywatelskich organizacji pozarządowych. Działo się to podczas V Europejskiej Konferencji Ministrów Odpowiedzialnych za Dziedzictwo Kulturowe, która odbyła się w Portorożu (Słowenia). Tamże sformułowano deklarację o roli dobrowolnych organizacji na polu dziedzictwa kulturowego przy uwzględnieniu zasad praw człowieka, respektowaniu prawa i demokracji pluralistycznego społeczeństwa. W czasie Konferencji dokonano oceny funkcji, jakie w odczuciu społeczeństwa europejskiego powinno spełniać dziedzict wo kulturowe w dobie gwałtownie zmieniającego się świata. Położono przy tym duży nacisk na rolę społeczeństwa obywatelskiego, dobrowolność oraz partnerstwo między sektorami: publicznym, prywatnym i wolontariatem, a także na pryncypia Rady Europy.

Europejskie zainteresowanie problematyką dziedzictwa kulturowego zbiegło się zresztą z działaniami UNESCO w tym zakresie, że wymienimy Konwencję UNESCO o Ochronie Niematerialnego Dziedzictwa Kulturowego 
(17.10.2003) ${ }^{10}$ czy Konwencję UNESCO o Ochronie i Promowaniu Różnorodności Form Wyrazu Kulturowego (20.10.2005).

Kamieniem milowym w unijnej polityce społeczno-kulturowej okazała się jednakże Konwencja Ramowa Rady Europy w Sprawie Wartości Dziedzictwa Kulturowego dla Społeczeństwa [Council of Europe Framework Convention on the Value of Cultural Heritage for Society], podpisana 27.10.2005 r. w Faro (Portugalia). Konwencja ta w sposób oczywisty nawiązywała do Europejskiej Konwencji Kulturalnej z 1954 r., Konwencji o Ochronie Dziedzictwa Architektonicznego w Europie (z r. 1985 i 1992) i Europejskiej Konwencji Krajobrazowej (z 2000 r.), z drugiej zaś strony formułowała zupełnie nowe podejście do omawianej materii. Dotychczasowe bowiem Konwencje zajmowały się jedynie problemem ochrony i konserwacji dóbr kultury, podczas gdy Konwencja Faro postawiła zasadnicze pytanie: dlaczego, przez kogo i dla kogo dziedzictwo jest przekazywane? Podstawę takiego ujęcia stanowił pogląd, że wiedza na temat dziedzictwa kulturowego i płynące stąd pożytki tworzą - między innymi - obywatelskie prawo do swobodnego uczestnictwa w życiu kulturalnym społeczeństwa (zgodnie z art. 27. Powszechnej Deklaracji Praw Człowieka).

Tekst Konwencji Faro w art. 2 definiuje „dziedzictwo kulturowe” jako:

zbiór zasobów odziedziczonych z przeszłości, które są dla ludzi tożsame - niezależnie od prawa własności - z odzwierciedleniem i wyrazem ich własnych, nieustannie ewoluujących wartości, wierzeń, wiedzy i tradycji. Zawiera ono [dziedzictwo - przyp. moje V.K.-W.] wszystkie aspekty środowiskowe wynikające z interakcji pomiędzy człowiekiem i miejscem w ciągu dziejów.

W tym samym artykule pojawia się nowe pojęcie "wspólnoty dziedzictwa" [heritage community], które definiowane jest jako:

składające się z ludzi ceniących wartość specyficznych aspektów dziedzictwa kulturowego i życzących sobie by - poprzez aktywność publiczną - dziedzictwo było podtrzymywane i przekazywane następnym pokoleniom.

Jak wynika z powyżej cytowanych definicji Konwencja Faro traktuje dziedzictwo kulturowe holistycznie. Tak więc relacja: człowiek - miejsce (otoczenie/środowisko naturalne) wraz z pojęciem przekazu międzypokoleniowego zawiera w sobie aspekt ekologiczno-antropologiczny. Z kolei

${ }^{10}$ H. Jodełka, Międzynarodowa ochrona niematerialnego dziedzictwa kulturowego, „Stosunki Międzynarodowe - International Relations” 2005, nr 3-4; taż, Instrument ochrony twórczości ludowej - Konwencja UNESCO z 2003 r., „Twórczość Ludowa” 2010, nr 3-4. 
klaster różnorodności i komplementarność jego zasobów oraz dostępność publiczna (bez względu na aktualnego właściciela) wskazuje na demokratyczne ideały powszechności dóbr wyższych. Postulat postępowania wobec zasobów dziedzictwa materialnego i niematerialnego obejmuje: identyfikowanie, inwentaryzowanie i dokumentację, badania naukowe, interpretację, ochronę, konserwację, prezentację i upowszechnianie oraz debatę publiczną nad wykorzystaniem potencjału tkwiącego w dziedzictwie.

Dalsze preambuły omawianego dokumentu dotyczą pojęcia wspólnego dziedzictwa Europy, rozumianego w kategorii praw i obowiązków poszczególnych społeczeństw i pojedynczych obywateli, polityki promocyjnej i strategicznej oraz prawnej ${ }^{11}$. W tekście Konwencji podkreślono konieczność dialogu międzykulturowego w atmosferze wolności i zachowań etycznych, powszechnej edukacji, wymiany informacji, poszerzania wiedzy, popularyzacji osiągnięć i współpracy oraz monitoringu i mechanizmów kontrolnych. Ponieważ postulat szerokiej partycypacji społecznej wskazuje wyraźnie, że podmiotowym beneficjentem dziedzictwa jest samo społeczeństwo, przeto Konwencja nadaje dziedzictwu wartość moralną i ekonomiczną, mającą służyć dobru pojedynczych, lokalnych wspólnot, a także sprzyjać procesowi tworzenia społeczności transgranicznych. Zasoby materialne i niematerialne dziedzictwa europejskiego stanowią także - co zostało podkreślone - wkład do zrównoważonego rozwoju ludzkości.

Konwencja Faro utorowała drogę dalszym inicjatywom Rady Europy i jej Komitetowi do Spraw Dziedzictwa, przede wszystkim zaś uaktywniła siły społeczne działające w ramach tzw. europejskiego społeczeństwa obywatelskiego ${ }^{12}$. Jak wiadomo nie wszystkie narody europejskie miały jednakową możliwość swobodnego rozwoju demokratycznego, w wyniku którego istnienie i ukształtowanie dojrzałego społeczeństwa partycypacyjnego uważane jest za fakt oczywisty. Stąd też nie we wszystkich państwach europejskich i w niejednakowym stopniu idee ochrony i kontynuacji dziedzictwa kulturowego znajdują swoich protagonistów działających aktywnie

${ }^{11}$ Por. K. Zalasińska, Prawna ochrona dziedzictwa kulturowego w Polsce, „Studia Iuridica”, nr 50, 2009, s. 195-206; Prawna ochrona dziedzictwa kulturowego, t. III., pod red. W. Szafrańskiego i K. Zalasińskiej, Wydawnictwo Poznańskie, Poznań 2009.

${ }_{12}$ Por. V. Krawczyk-Wasilewska, Ochrona dziedzictwa kulturowego a społeczeństwo obywatelskie w świetle polityki Unii Europejskiej, [w:] Jakość wobec wyzwań i zagrożeń XXI wieku, pod red. R. Reclik i A. Zduniaka, Wydawnictwo Wyższej Szkoły Bezpieczeństwa, Poznań 2010, s. $268-273$. 
w ramach dobrowolnych organizacji obywatelskich. Z kolei wiele organizacji pozarządowych koncentruje się li tylko na wyrwanej z szerszego kontekstu problematyce lokalnej ${ }^{13} \mathrm{i}$ pomija aspekt europejski oraz globalny lub nie odczuwa konieczności współpracy i wymiany doświadczeń z podobnymi organizacjami na szczeblu krajowym i międzynarodowym. Nie dostrzega wreszcie tzw. wartości dodanej tkwiącej w pracy na polu dziedzictwa kulturowego. Dziedzictwo kulturowe bowiem jest chronione dla ludzi (a nie dla samej idei) i stanowi element lobbingu, edukacji oraz rozwoju w demokratycznej, wielokulturowej wspólnocie, tym samym dając miejsca pracy określonym specjalistom oraz wpływając na rozwój wielu dziedzin o charakterze ekonomicznym, jak choćby turystyka, transport, gastronomia itp.

Na uwagę zasługuje także decyzja Parlamentu Europejskiego i Rady Europy z listopada 2011 r., ustanawiająca Znak Dziedzictwa Europejskiego [European Heritage Label] przyznawany znajdującym się na terytorium Unii obiektom odgrywającym istotną rolę $\mathrm{w}$ historii, kulturze oraz w budowaniu Unii. Celem tej inicjatywy było wzmocnienie poczucia przynależności do Unii wśród obywateli oraz wzmocnienia dialogu między kulturami. Nacisk położono na europejską wartość symboliczną obiektów i ich wymiar pedagogiczny, tym samym odróżniając Znak Dziedzictwa Europejskiego od inicjatyw w zakresie dziedzictwa realizowanych przez UNESCO. Do przyznania znaku kwalifikują się zabytki, miejsca naturalne, obiekty podwodne, archeologiczne, przemysłowe lub miejskie, krajobrazy kulturowe, miejsca pamięci, dobra i obiekty kultury oraz dziedzictwo niematerialne związane z danym miejscem, w tym dziedzictwo współczesne. Pierwsze Znaki Dziedzictwa Europejskiego przyznane będą w 2013 r. w wyniku konkursu projektów.

W chwili obecnej w 35 państwach europejskich istnieje ponad 340 organizacji pozarządowych zajmujących się problematyką dziedzictwa kulturowego w aspekcie europejskim i pozaeuropejskim, unijnym, transnarodowym, narodowym, regionalnym i pogranicznym. Dane te są wynikiem rejestracji tych stowarzyszeń i fundacji w unijnym projekcie pod nazwą

${ }^{13} \mathrm{Z}$ braku ugruntowanej tradycji tzw. trzeciego sektora, działalność polskich organizacji pozarządowych często nie osiąga zadowalających rezultatów, nawet na gruncie lokalnym. Por. np. B. Sludkowska, J. Wacławiak, J. Trojanowska, Promocja Łodzi na przykładzie działalności instytucji lokalnych, [w:] Kultura jako czynnik rozwoju miasta na przykładzie Łodzi, pod red. V. Krawczyk-Wasilewskiej, M. Kucner, E. Zimnica-Kuzioły, Wydawnictwo UŁ, Łódź 2013, s. 175-179. 
Inventory of Heritage Organisations in Europe (IHOE) ${ }^{14}$, który w swej siedzibie w Mechelen (Belgia) od 2008 r. zajmuje się ich inwentaryzowaniem, a także propagowaniem ich pracy (np. poprzez konferencje i materiały szkoleniowe). Działalność wspomnianych organizacji odzwierciedla szeroką definicję dziedzictwa: od architektury, poprzez transport, technikę, historię (społeczną, ekonomiczną, polityczną, militarną, heraldykę), muzealnictwo, archiwistykę, regionalistykę, kulturę ludową i etniczną, etnologię, folklor i kulturę oralną, język, edukację, życie teatralne, muzyczne, gastronomię, tradycyjne zawody, dziedzict wo digitalne i audiowizualne oraz wiele innych.

Większość organizacji, zajmujących się problematyką kulturową łączy się w sieci. Najstarsza sieć przyjęła nazwę Europa Nostra; powstała w 1963 r. z siedzibą w Paryżu, którą w 2010 r. przeniesiono do Brukseli. Europa Nostra jest europejską federacją stowarzyszeń, których celem jest propagowanie oraz ochrona dziedzictwa kulturowego i środowiska naturalnego w Europie. Federacja składa się z 400 organizacji członkowskich, działających w 45 krajach europejskich. Pojedyncze organizacje członkowskie często reprezentują współpracujące z nimi struktury pozarządowe i non-profit, a także przedsiębiorstwa prywatne i publiczne oraz pojedyncze podmioty działające w skali europejskiej, narodowej, regionalnej i lokalnej. Dzięki przynależności do sieci Europa Nostra wiele mniejszych stowarzyszeń, działających na szczeblu lokalnym ma możliwość komunikowania się z dużymi instytucjami, takimi jak Unia Europejska, Rada Europy, czy globalne UNESCO. Wśród organizacji członkowskich Polskę reprezentują następujące: Patria Polonorum z Warszawy, Międzynarodowe Centrum Kultury z Krakowa, Towarzystwo Przyjaciół Historii i Pomników z Krakowa, Towarzystwo Przyjaciół Warszawy, Academia Europa Nostra z Lubieszynka, Dobro Kultury. Fundacja dla Ochrony Dziedzictwa Kulturowego ze Słubic, Zespół Pałacowy Kurozwęki - Staszów Sp. z o.o. oraz Fundacja Zamek Chudów.

Od 1978 r. stowarzyszenie federacyjne Europa Nostra wręcza nagrody za utrzymywanie i restaurację obiektów kultury w krajach europejskich. W 2002 roku Rada Europy przekazała stowarzyszeniu nadzór nad administracją programu nagród zwanego European Union Prize for Cultural Heritage („Nagroda Europa Nostra”). Celem tego programu jest:

${ }_{14}$ Por. też zorganizowany przez Michael Association (2007) Multilingual Inventory of Cultural Heritage in Europe (tzw. Michael). Patrz wersja polska na: www.michael-culture.org (dostęp: 31.05.2013). 
- promowanie wysokich i rygorystycznych standardów na polu dziedzictwa kulturowego Europy;

- stymulowanie wymiany doświadczeń i kompetencji na poziomie ponadnarodowym;

- stymulowanie działań i akcji w ramach rozwoju dziedzictwa kulturowego.

Nadmienić tu należy, że dotychczas nagrodzono 15 polskich obiektów architektonicznych i muzealnych, a prezes organizacji Patria Polonorum Zygmunt Świechowski zasiada w Radzie Naczelnej Europa Nostra.

Młodszą siostrą Europy Nostry była sieć European Forum for Artistic Heritage (EFAH), zarejestrowana w 1992 r., a od roku 2008 przekształcona w Culture Action Europe (z siedzibą w Brukseli). Culture Action Europe zrzesza 90 organizacji członkowskich reprezentujących 14 dyscyplin artystycznych w ramach działalności ponad 10.000 towarzystw związanych ze sztukami pięknymi, muzyką, teatrem, filmem itp. oraz organizuje integracyjne festiwale i konferencje (np. słynny The Time is Now! - 7-10 października 2010). Wśród członków tej sieci znajdują się 3 polskie organizacje: Centrum Artystyczne Fabryka Trzciny. Sp. z o.o. z Warszawy, Fundacja ARTeria z Zabrza i Nadbałtyckie Centrum Kultury z Gdańska.

Osobną uwagę należy poświęcić sieci The European Heritage Network (HEREIN) zorganizowanej przez Radę Europy w 1999 r., która stanowi unijny system informacyjny na temat organizacji rządowych odpowiedzialnych za problematykę dziedzictwa. System danych obejmuje informacje o instytucjach państwowych, funduszach i strategiach oraz ekspertach, badaczach i organizacjach formalnych, ale też o organizacjach pozarządowych związanych z ochroną i konserwacją dziedzictwa kulturalnego i naturalnego. Jeśli idzie o polskie organizacje pozarządowe, system HEREIN wykazuje: Towarzystwo Opieki na Zabytkami, Polskie Towarzystwo Turystyczno-Krajoznawcze i Społeczny Komitet Odnowy Zabytków Krakowa. W systemie sieci HEREIN znajduje się też tezaurus, obejmujący 500 terminów specjalistycznych w 11 językach. Poza wymienioną wyżej dokumentacją, system popularyzuje tematykę dziedzictwa poprzez wirtualne prezentacje i wystawy. HEREIN specjalizuje się głównie w dziedzictwie archeologicznym i architektonicznym. 
Wspominając polskie organizacje obywatelskie, zajmujące się dziedzictwem kulturowym nie wymieniliśmy z nazwy wszystkich, które istnieją. Część z nich bowiem jest od lat członkami lokalnymi i oddziałami większych, międzynarodowych stowarzyszeń, np. Polska Sekcja CIOFF - Conseil International des Organisations de Festivals de Folklore et d' Art Traditionnels, czy ICOMOS Poland - Polski Komitet Narodowy Międzynarodowej Rady Ochrony Zabytków [International Council on Monuments and Sites], niektóre zaś zajmują się dziedzictwem kulturalnym niejako pośrednio, poprzez kształtowanie (zwłaszcza u dzieci i młodzieży) postaw demokratycznych i obywatelskich, tak jak czyni to organizacja pożytku publicznego - Fundacja „Centrum Edukacji Obywatelskiej” z Warszawy, czy projekty niewielu uczelni wyższych, wpisujących się do programu unijnego Dyrekcji Generalnej ds. Edukacji i Kultury w ramach projektów: Kształcenie ustawiczne („Edukacja i kształcenie w centrum uwagi”), Młodzież $w$ działaniu („Młodzież”), Pielęgnowanie korzeni kultury europejskiej, W kierunku tożsamości europejskiej („Kultura”), Budowanie Europy obywatelskiej („Obywatelstwo”).

W niniejszym artykule nie dokonaliśmy liczbowego porównania polskich organizacji pozarządowych zajmujących się dziedzictwem w stosunku do liczby analogicznych organizacji winnych państwach europejskich. Z pobieżnego jednak przeglądu wynika, że takich obywatelskich stowarzyszeń, fundacji, itp. jest w Polsce wciąż niewiele, zwłaszcza obecnie w toku trwania (od 01.01.2007 do 31.12.2013) programu Komisji Europejskiej nazwanego „Europa dla Obywateli” z całkowitym budżetem 215 milionów euro przy aktywnym wsparciu innej agendy Komisji - Dyrektoriatu Generalnego Edukacja i Kultura, którym od 2010 r. kieruje w Brukseli Jan Truszczyński.

Na szczególną uwagę zasługuje fakt, iż projekty obywatelskie w zakresie dziedzictwa kulturowego nie mają w naszym kraju odpowiedniej recepcji, tak w mediach, jak i wśród samych obywateli, którzy niedostatecznie wierzą we własne możliwości, w potęgę kontaktów i współpracy, dialog interkulturowy oraz wsparcie unijne. Wydaje się więc, że sytuacja dojrzała do zmiany, dlatego też postulujemy, by w toku pracy uczelnianej zachęcać młodzież akademicką (zwłaszcza antropologów kultury i etnologów) do aktywnego, obywatelskiego zrzeszania się i działania na polu dziedzictwa, choćby w skali „micro”. Często działania takie sprzyjają „drążeniu skały” i zmianie postaw władz lokalnych, które - pod wpływem lobbingu trzeciego sektora 
- doceniają konieczność nie tylko podtrzymywania, konserwacji i ochrony zabytków kultury, ale także rozwoju i przekształcania środowiska pod kątem kultury historycznej i artystycznej oraz materialnej i niematerialnej pamięci społecznej. Nie bez znaczenia jest też tworzenie wartości dodanej poprzez rozwój turystyki i biznesu, zatrudnianie humanistów, otwarcie na zewnątrz. Od lokalnych światów do globalnej wioski...

\section{BIBLIOGRAFIA}

- Bednarek S., W kręgu małych ojczyzn. Szkice regionalistyczne, KODRTK, Wrocław -Ciechanów 1996.

- Cohen A., SelfConsciousness: An Alternative Anthropology of Identity, Routledge, London 1994.

- Erikson E. H., The Problem of Ego Identity, „Journal of American Psychoalalytical Association" 1956, nr 4.

- Erikson E. H., Identity and Life Cycle. Selected Papers, Intl. Univ. Press, New York 1959.

- Globalizacja i integracja europejska, pod red. B. Jóźwika, Wydawnictwo KUL, Lublin 2007.

- Ja - regionalista. Refleksje, stanowiska, komentarze, pod red. D. Kasprzyka, Interdyscyplinarny Zespół Badania Wsi UŁ, Łódź 2010.

- Jodełka H., Instrument ochrony twórczości ludowej - Konwencja UNESCO z 2003 r., „Twórczość Ludowa" 2010, nr 3-4.

- Jodełka H., Międzynarodowa ochrona niematerialnego dziedzictwa kulturowego, „Stosunki Międzynarodowe - International Relations” 2005, nr 3-4.

- Krawczyk-Wasilewska V., Ochrona dziedzictwa kulturowego a społeczeństwo obywatelskie w świetle polityki Unii Europejskiej, [w:] Jakość wobec wyzwań i zagrożeń XXI wieku, pod red. R. Reclik i A. Zduniaka, Wydawnictwo Wyższej Szkoły Bezpieczeństwa, Poznań 2010.

- Krawczyk-Wasilewska V., Tożsamość podmiotu zbiorowego w dobie globalizacji. Wybrane zagadnienia, [w:] Zagrożenie tożsamości? Problematyka globalizacji w zainteresowaniach polskiej antropologii, pod red. A. Nadolskiej-Styczyńskiej, seria wyd. „Archiwum Etnograficzne", t. 43, PTL, Wrocław-Łódź 2005.

- Prawna ochrona dziedzictwa kulturowego, t. III., pod red. W. Szafrańskiego i K. Zalasińskiej, Wydawnictwo Poznańskie, Poznań 2009.

- Pruszyński J., Dziedzictwo kultury Polski. Jego straty i ochrona prawna, t. 1-2, Wydawnictwo Zakamycze, Kraków 2001.

- Robertson R., Globalization: Social Theory and Global Culture, Sage, London 1992; Z. Bauman, Globalizacja i co z tego dla ludzi wynika, PIW, Warszawa 2007.

- Sludkowska B., Wacławiak J., Trojanowska J., Promocja Łodzi na przykładzie działalności instytucji lokalnych, [w:] Kultura jako czynnik rozwoju miasta na przykładzie Łodzi, pod red. V. Krawczyk-Wasilewskiej, M. Kucner, E. Zimnica-Kuzioły, Wydawnictwo UŁ, Łódź 2013. 
- The Globalization of World Politics: An Introduction to International Relations, pod red. J. Baylisa i S. Smitha, Oxford Univ. Press, Oxford 1997.

- The Politics of Multiculturalism in the New Europe: Racism, Identity and Community, pod red. T. Modooda i P. Werbnera, Zed Books, London 1997.

- Wieruszewska M., Tożsamość kulturowa jako wartość i czynnik konstruktywny społeczności lokalnej, Wydawnictwo Uniwersytetu Warszawskiego, Warszawa 1989.

- Woodward K., Questioning Identity: Gender, Class, Ethnicity, Routledge, London 2004.

- Zalasińska K., Prawna ochrona dziedzictwa kulturowego w Polsce, „Studia Iuridica”, nr 50, 2009.

- www.Europa.eu/en-law/treaties/index_pl (dostęp: 31.05.2013).

- www.michael-culture.org (dostęp: 31.05.2013).

\section{FROM LOCAL TO GLOBAL: EUROPEAN CULTURE HERITAGE AND EU POLICY}

The notion of ethnic and cultural identity has modern connotations that give the problem of identity new meaning. On the one side there is consideration of human rights and acceptance of individual and collective identity. On the other, there are the social, political, and economic problems connected with European integration and progressive globalization. The concept of European cultural integrity and mutual cultural heritage emerged after World War II in response to war crimes and deficiencies in the existing international laws and conventions. In this article, the author gives a short outline of relevant European documents, such as acts, conventions, and programs dealing with the problem of cultural diversity and unity. The author gives special attention to the aspect of common culture heritage, both tangible and intangible, and underlines that EU policy treats safeguarding, protection, and conservation of cultural heritage both as an obligation of European member states and as an ongoing activity of citizens, in the frame of heritage NGOs. 